\title{
Epigenetics and Codon Usage of the Histone Genes in 12 Drosophila Species
}

\author{
Yoshinori Matsuo* \\ Division of Science and Technology, Tokushima University, Tokushima 770-8506, Japan
}

*Corresponding author: Matsuo Y, Division of Science and Technology, Tokushima University, 2-1 Minamijosanjima-cho, Tokushima 770-8506, Japan, Tel: +81-88-656-7270; E-mail: matsuo.yoshinori@tokushima-u.ac.jp

Receiving date: April 12, 2017, Acceptance date: May 02, 2017, Publication date: May 15, 2017

Copyright: (c) 2017 Matsuo Y. This is an open-access article distributed under the terms of the Creative Commons Attribution License, which permits unrestricted use, distribution, and reproduction in any medium, provided the original author and source are credited.

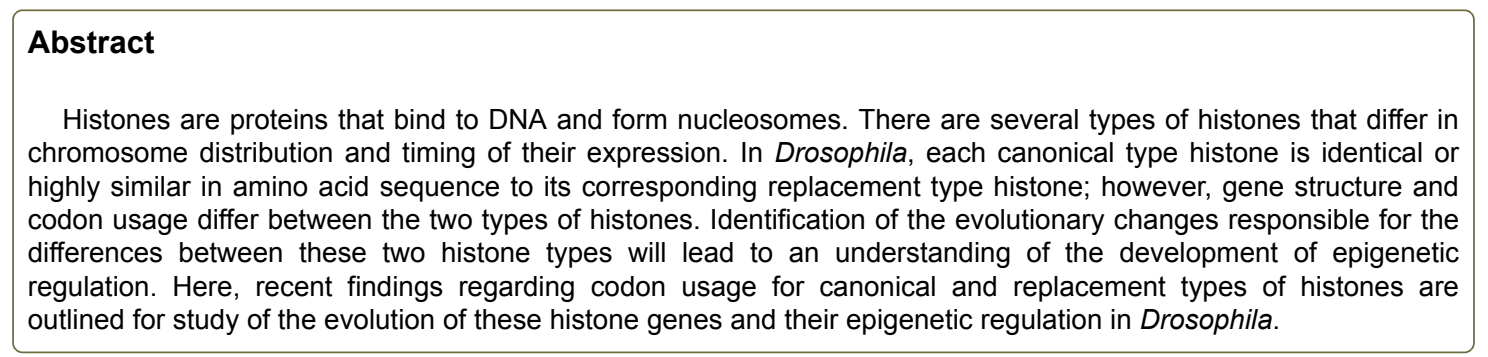

Keywords: Histone gene; Codon usage; Drosophila; GC content; Epigenetics

\section{Introduction}

The molecular mechanism of epigenetics caused by histone modification and replacement is one of the important problems to be solved in the fields of cell biology and molecular biology. Several types of histones are found in Drosophila; one type is expressed dependently with chromosome replication, another type is expressed independently, and other types are histones specific for the centromere region (CEN-P) or are histone-like proteins [1-11]. Most of the early histone studies investigated the replication-dependent type in sea urchin, Xenopus and Drosophila, and therefore this type is called a 'canonical' histone. The other histone type, which is expressed independently of replication, was called a 'variant' or a 'replacement' because of some amino acid substitutions compared to the corresponding canonical histone [12]. The codon usage for the two histone types is reviewed here; however, many interesting results have also been reported regarding $\mathrm{CEN}-\mathrm{P}$ and histone-like proteins [3,5,11,13-17]. In addition to the normal 'functional' histone genes, broken genes or pseudogenes have also been found in a genome [18]. The histone genes for canonical histones in Drosophila have been reviewed elsewhere [19]. These genetic differences will be helpful for understanding the evolution of these histone genes and their epigenetic systems in Drosophila.

\section{Modification and Replacement for Histones}

Information other than that on the genetic level has been found to be related to a variety of biological phenomena such as gene expression and cell differentiation [20-28]. Histone modifications and replacements belong to such mechanisms [25,26,29-39]. A chromosome is formed from chromatin, which is modelled from histones and DNA [40,41]. Chromatin remodeling is triggered by subtle changes in nucleosome structure such as modification/ unmodification of amino acids or replacement histones [29,32,42-50].
Histone modifications occur at Lys, Arg, Thr, and Ser sites by modifications such as methylation, acetylation, phosphorylation, and ubiquitylation. Effects of histone modifications on chromatin remodeling differ significantly depending on which amino acid is modified or unmodified, which amino acid position is modified, and what kind of modification or unmodification occurs [24,30,51-54]. A replacement of a histone with a different type of histone also causes chromatin remodeling [12,50,55-64].

In Drosophila melanogaster five histones, $\mathrm{H} 1, \mathrm{H} 2 \mathrm{~A}, \mathrm{H} 2 \mathrm{~B}, \mathrm{H} 3$, and $\mathrm{H} 4$, are known as canonical type histones $[1,40]$ and four histones, $\mathrm{H} 2 \mathrm{AvD}, \mathrm{H} 3.3 \mathrm{~A}, \mathrm{H} 3.3 \mathrm{~B}$, and $\mathrm{H} 4 \mathrm{r}$ are known as replacement type histones (Table 1) [65-68]. A replacement type for $\mathrm{H} 2 \mathrm{~B}$ has not yet been found in Drosophila; however, a pseudogene for H2B was found [18].

\begin{tabular}{|l|l|}
\hline Canonical Type & Replacement Type \\
\hline H1 & - \\
\hline H2A & H2AvD \\
\hline H2B & - \\
\hline H3 & H3.3A, H3.3B \\
\hline H4 & H4r \\
\hline
\end{tabular}

Table 1: Genes for canonical type histones and their corresponding replacement type histone in Drosophila.

\section{Gene Structure for the Canonical and Replacement Histone Types in Drosophila}

Large differences in the structural genes of histones in Drosophila have been found between the canonical and replacement histone types [65-72]. The structures of the genes for the canonical histone types in D. melanogaster, a typical species of Drosophila, are shown in Figure 1 and those for the replacement types are shown in Figure 2. The basic 
structure of histone genes seems to be the same among different Drosophila species [71-78].

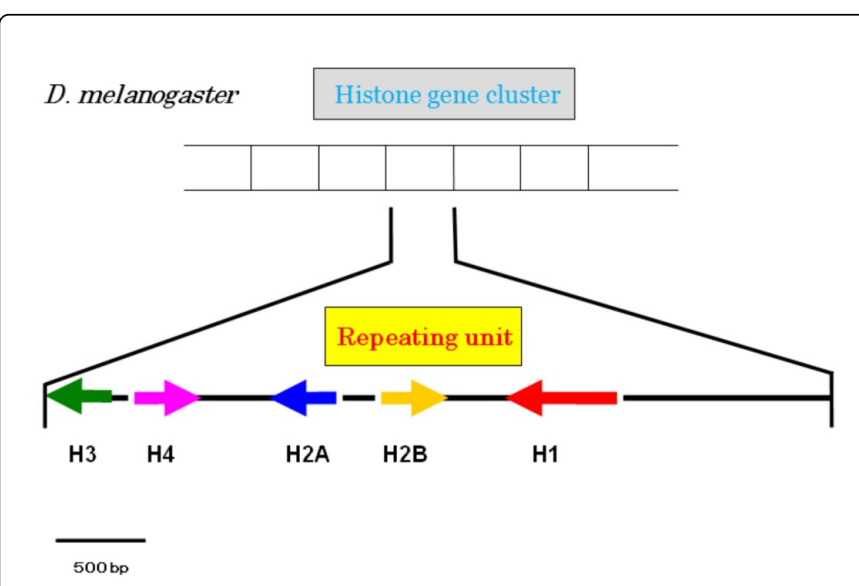

Figure 1: Structure of the genes for the canonical type histones in Drosophila melanogaster. A repeating unit encodes the five histone genes and is repeated about 110 times. Arrows show the direction of transcription.

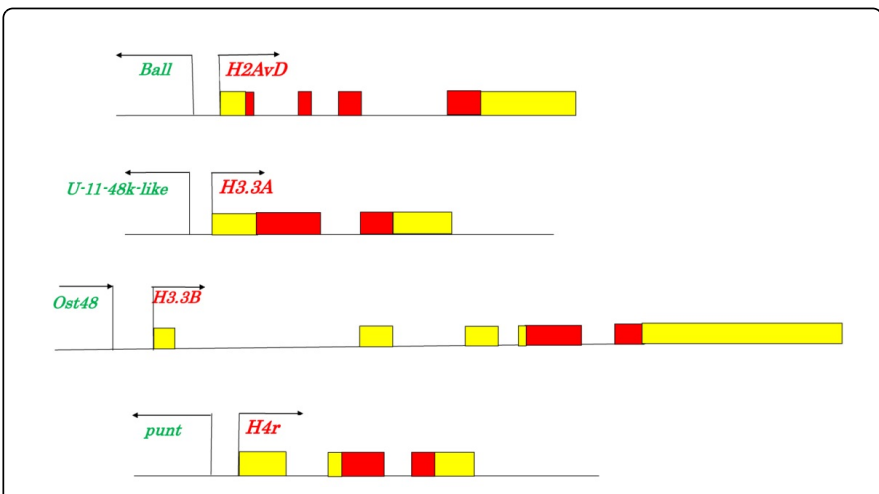

Figure 2: Structure of the genes for the replacement type histones in Drosophila melanogaster. The coding region is colored red and the untranslated region is colored yellow. The orientation of transcription is indicated by arrows.

Genes for the canonical histone type are clustered by tandem duplication, and a repetitive unit is $5 \mathrm{~kb}(\mathrm{~L})$ or $4.8 \mathrm{~kb}(\mathrm{~S})$ in $D$. melanogaster. The difference between the $\mathrm{L}$ and $\mathrm{S}$ units is due to the presence or absence of a tRNA-derived element [69]. The histone gene cluster is located at the D-E region of chromosome II and the unit is repeated more than 100 times $[79,80]$. An ordinary repeating unit codes for 5 histone genes, termed a 'quintet' (H1, H2A, H2B, H3, and $\mathrm{H} 4$ ), and an exceptional unit codes for 4 histone genes, termed a 'quartet' (H2A, H2B, H3, and H4). In Drosophila virilis and Drosophila americana, quintets and quartets coexist in the genome $[27,75,81,82]$. A similar quartet cluster was also found in Mytilus edulis [83]. The repeating units of the cluster in a species are highly similar in terms of DNA sequence and have evolved in a concerted fashion $[70,74,77]$. No intron has been found for any gene for the canonical histone type. A hair-pin loop structure is present in the downstream region of each histone gene and transcription stops at that point $[69,84]$. A poly(A) tail is not usually added in the transcripts of canonical histones [85] although some exceptions have been reported [86]. The presence of a signal for polyadenylation has been indicated $[69,86]$.

On the other hand, the genes for the replacement type histones are either single copy ( $\mathrm{H} 2 \mathrm{AvD}$ and $\mathrm{H} 4 \mathrm{r}$ ) or a few copies (H3.3A and H3.3B) [65-68], and have evolved independently of those for the canonical type [87-89]. These histone genes are split by 1-4 introns [65-68] (Figure 2) and a poly(A) tail is added to the transcripts [65,67].

\section{The GC Content at the $3^{\text {rd }}$ Codon Position of the Histone Genes in Drosophila}

The GC content at the $3^{\text {rd }}$ codon position of the genes for the canonical and replacement histone types was analysed and compared for 12 Drosophila species [87-89] for which the genome project has already been completed. Analyses for the $\mathrm{H} 1$ and $\mathrm{H} 2 \mathrm{~B}$ genes have not been presented before because of the absence of corresponding replacement histones. Results for these genes are shown together with those for the other histone genes in Figure 3. The GC content at the $3^{\text {rd }}$ codon position is clearly affected by at least two factors; one factor is 'species' and the other factor is 'genes' $[76,90,91]$. In the species comparison, the GC content for any histone gene in Drosophila willistoni was considerably lower than that for other species (Figure 3). The same tendency for a drop in GC value in $D$. willistoni has been reported for other genes $[92,93]$. Table 2 shows the GC content at the $3^{\text {rd }}$ codon position for each histone gene averaged over the 12 Drosophila species. For any comparison of canonical and replacement type histones, the GC content of the replacement type is always higher than that of the canonical type. Comparison of the average GC content of the two types shows that the average GC content is $8.9 \%$ higher in the replacement type (62.8\%) than that in the canonical type (53.9\%) (Figure 3 and Table 2). The highest GC content among the canonical types was observed for $\mathrm{H} 2 \mathrm{~B}(61.7 \%)$. The reason for this finding is not known. One possibility is the absence of a corresponding replacement type in spite of the fact that H2B is a core histone. The lowest GC content among the canonical types was observed for H1 (48.0\%). This finding is probably related to the fact that the expression level of $\mathrm{H} 1$, which functions as a linker, is half that of the core histones. As described below, the GC content at the 3rd codon position is relevant to the usage of codons.

\begin{tabular}{|l|l|l|l|}
\hline Histone gene & Canonical type & \multicolumn{2}{l|}{ Replacement type } \\
\hline $\mathrm{H} 1$ & 0.480 & - & - \\
\hline $\mathrm{H} 2 \mathrm{~A}$ & 0.529 & - & 0.617 \\
\hline $\mathrm{H} 2 \mathrm{~B}$ & 0.617 & - & - \\
\hline & & A & 0.667 \\
\cline { 2 - 4 } & 0.521 & B & 0.636 \\
\hline $\mathrm{H} 3$ & 0.491 & - & 0.591 \\
\hline Mean type & 0.527 & - & 0.628 \\
\hline $\begin{array}{l}\text { Mean type } \\
\text { (Without H1) }\end{array}$ & 0.539 & - & - \\
\hline
\end{tabular}


Page 3 of 7

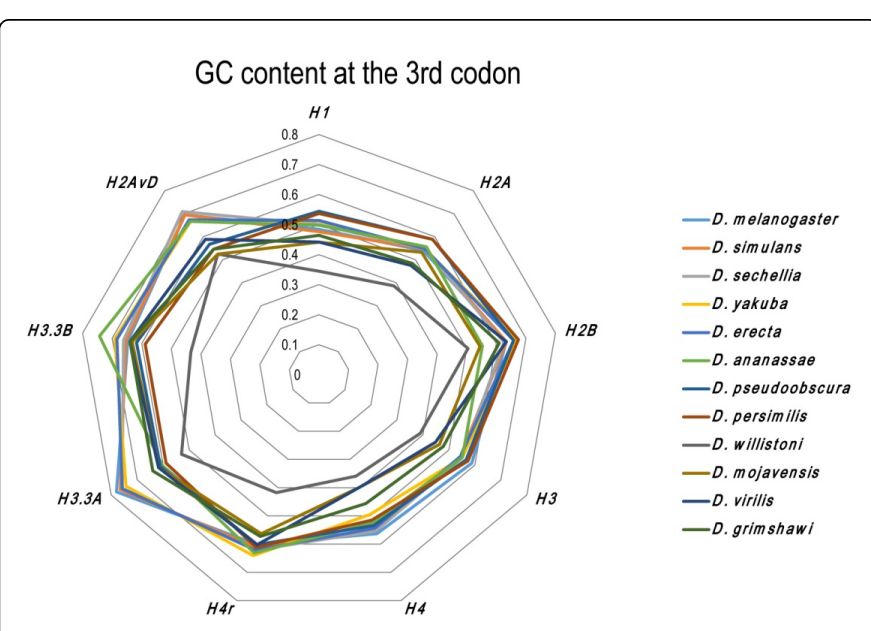

Figure 3: GC content at the third codon positions of the nine histone genes in Drosophila. The diagram shows the proportion of $\mathrm{G}$ or $\mathrm{C}$ at the third codon for each histone gene in 12 Drosophila species.

\section{Codon Usage of the Histone Genes in Drosophila}

Codon usage for nine histone genes, five canonical $(\mathrm{H} 1, \mathrm{H} 2 \mathrm{~A}, \mathrm{H} 2 \mathrm{~B}$, $\mathrm{H} 3$, and $\mathrm{H} 4)$ and four replacement $(\mathrm{H} 2 \mathrm{AvD}, \mathrm{H} 3.3 \mathrm{~A}, \mathrm{H} 3.3 \mathrm{~B}$, and $\mathrm{H} 4 \mathrm{r})$ genes is shown in Figure 4. A group of two synonymous codons is shown on the left-hand side. Groups of three, four, and six synonymous codons are shown on the right-hand side. For convenience, a $3^{\text {rd }}$ codon with $\mathrm{A}$ or $\mathrm{U}$ is indicated at the lower end of each bar, and a $3^{\text {rd }}$ codon with a $\mathrm{G}$ or $\mathrm{C}$ is indicated at the upper end of each bar. In this way, the GC content at the $3^{\text {rd }}$ codon can be imaged by summing the $\mathrm{G}$ and $\mathrm{C}$ blocks at the upper end of the bars. Codon usage cannot be compared for Cys, because of no usage or a small number. When codon usage of the two histone types is compared, generally speaking $\mathrm{G}$ or $\mathrm{C}$ is used more frequently at the $3^{\text {rd }}$ codon position for the replacement type than for the canonical type. In some exceptional cases, although the number of cases is small, the usage of a synonymous codon was almost the same for the two histone types (for example, in a comparison of codons for Glu between $\mathrm{H} 2 \mathrm{~A}$ and $\mathrm{H} 2 \mathrm{AvD}$, or of codons for Tyr between $\mathrm{H} 3$ and $\mathrm{H} 3.3 \mathrm{~B}$ ) or showed an inverse tendency (in comparisons of codons for Asp or Ile between H3, H3.3A, and H3.3B). Therefore, the GC content difference of the $3^{\text {rd }}$ codon between the two types seems to reflect a general tendency rather than reflect several unique usages for a specific amino acid.

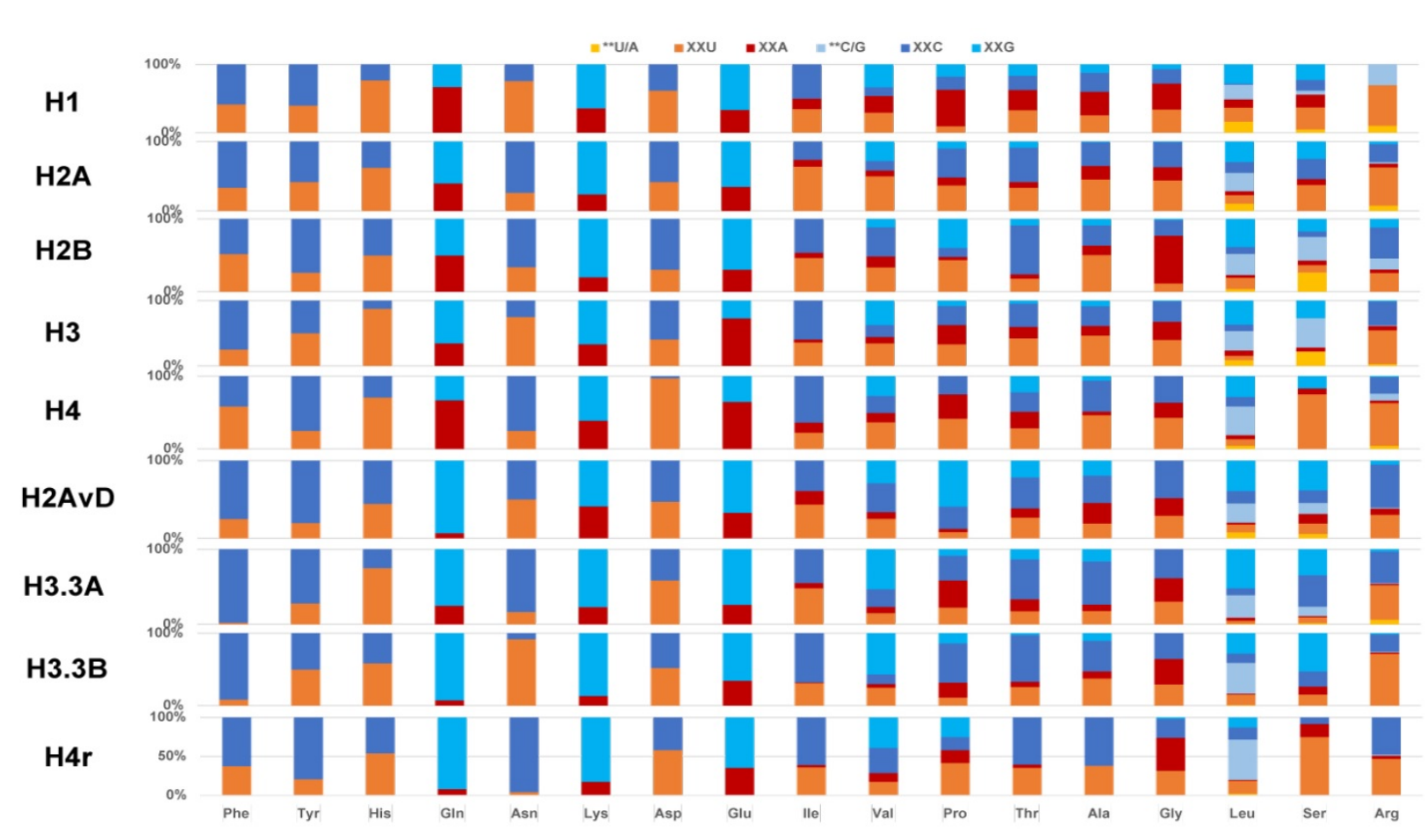

Figure 4: Comparison of the codon usage of nine genes for canonical and replacement histone types summed over 12 Drosophila species. The codon usage (\%) for each of 17 amino acids is indicated. The codon usage for cysteine is not compared because of the small number of cysteine use. The colour is based on the nucleotide at the 3rd position in the codon (XXU, XXA, XXC, and XXG). For amino acid groups with 6 synonymous codons, two more synonymous codons are shown based on the nucleotide at the third position in the codon, either U/A or C/G. These codons are indicated by ${ }^{* *} \mathrm{U} / \mathrm{A}$ and ${ }^{* *} \mathrm{C} / \mathrm{G}$, respectively.

\section{Codon Usage at the Histone Modification Sites}

The relationship between codon usage and histone modification (at Lys, Arg, Thr, or Ser) was analysed for four histones in Drosophila
[87-89]. The modification pattern of Lys was complicated because of many sites of modification; several kinds of modifications such as methylation, acetylation, phosphorylation, and ubiquitylation; and multiple modifications at a single site such as 1-3 methylations, 
methylation and acetylation [20,45,46,51,52,94]. Although the relationship was not clear-cut, when the codon AAA was frequently used, this Lys site tended to be modified.

Thirteen arginine sites are known to be methylated in a total of four histones. The amino acid at position 73 of $\mathrm{H} 2 \mathrm{~B}$ in Drosophila is substituted with a different amino acid from arginine and therefore this site is not methylated. At three arginine positions in canonical type histones, position 76 in $\mathrm{H} 2 \mathrm{~A}, 128$ in $\mathrm{H} 3$, and 92 in $\mathrm{H} 4$, the arginine codon AGA was used the most. All three of these positions were modified (Figure 5). Thus the codon AGA was used with a frequency of more than $50 \%$, only for modified sites. There may thus be a relationship between AGA codon usage and arginine methylation.

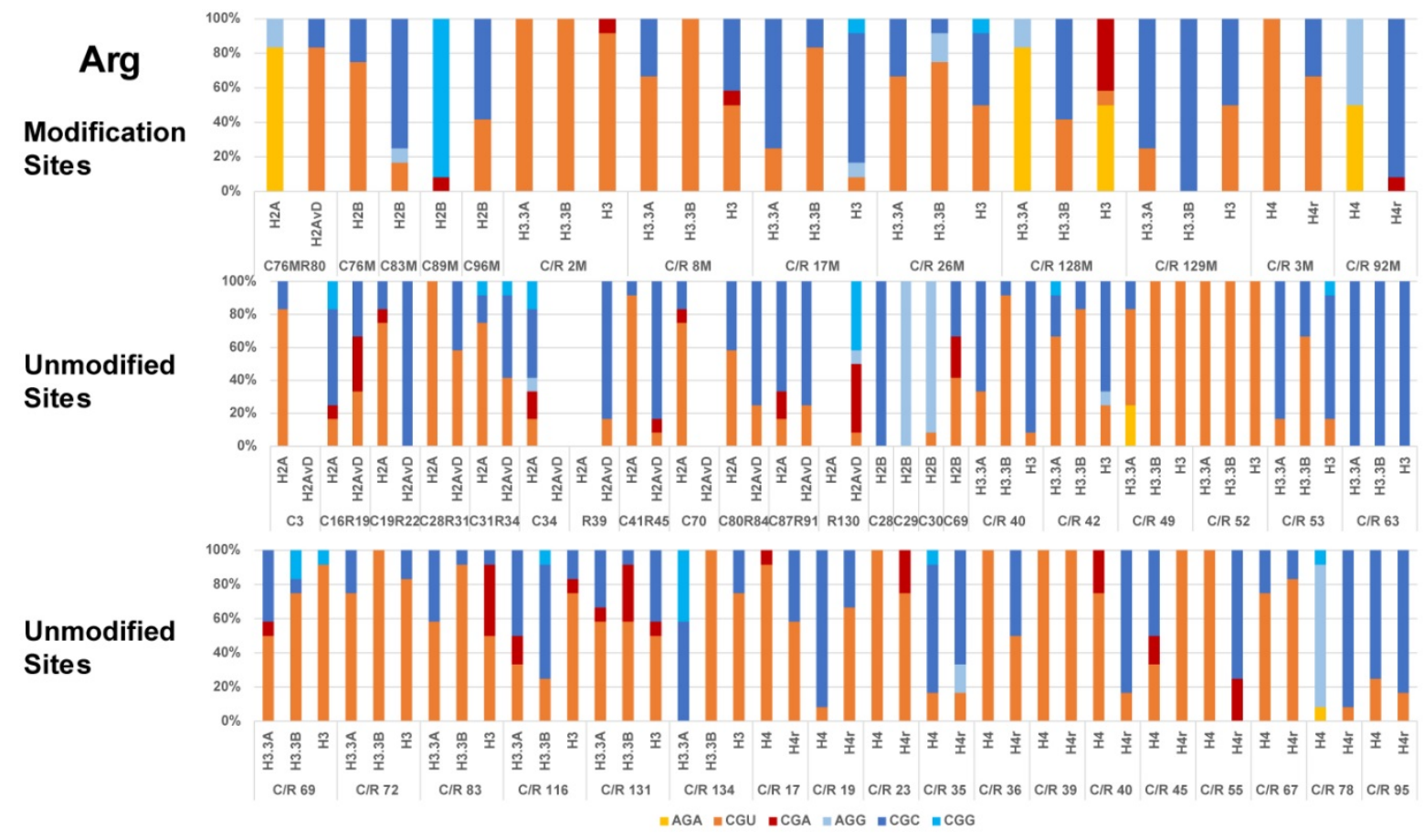

Figure 5: Codon usage for the modified or unmodified arginine sites in histones summed over 12 Drosophila species. The position numbers for arginines in the canonical $(\mathrm{C})$ or replacement $(\mathrm{R})$ histone types, and the codon usage for these arginines are indicated. The codon usages (\%) are labeled with the same colours as in Figure 4. The protein length of H2A in Drosophila differs from that of human/mouse H2A by six amino acids. Indels in human/mouse and Drosophila may cause gaps in the amino acid numbers defined from the $\mathrm{N}$-terminal end for each species; therefore, caution is needed regarding the amino acid position numbers of the modification sites. The " $\mathrm{M}$ " on the $\mathrm{X}$ axis refers to a site for methylation.

Five serine sites are phosphorylated in total (position 1 in $\mathrm{H} 2 \mathrm{~A}, 33$ in $\mathrm{H} 2 \mathrm{~B}, 10$ and 28 in $\mathrm{H} 3$, and 1 in $\mathrm{H} 4$ ). There is an amino acid substitution for the non-modified amino acid at position 14 of $\mathrm{H} 2 \mathrm{~B}$. For the canonical type, the codons UCU and AGU are used more than the other codons for serine at 7 sites, and 3 of these sites (position 1 in $\mathrm{H} 2 \mathrm{~A}, 28$ in $\mathrm{H} 3$, and 1 in $\mathrm{H} 4$ ) correspond to sites of serine modification (Figure 6). There is thus possibly a connection between the phosphorylation of serine and the usage of UCU and AGU codons.

Four threonine sites are phosphorylated in total (position 119 in $\mathrm{H} 2 \mathrm{~A}$, and 3,11 , and 118 in $\mathrm{H} 3$ ). There was no obvious tendency for specific codon usage for threonine. In Drosophila H4, the amino acid at position 47 is substituted with a non-modified amino acid and therefore this site would not be phosphorylated.

In the future, it is anticipated that new histone modifications and more biological meanings for histone modification will be found. As for the timing of these modifications, it was recently reported that a certain modification (H3K9) occurred during translation, but not post translation [95]. The possible connection between modification and codon use such as between methylation of Arg and the use of AGA, and between phosphorylation of Ser and UCU or AGU usage suggested that histone modification might be associated with a specific tRNA, leading to one of the modification mechanisms at a specific site in the protein. It is a possibility that some amino acids within histones are modified during translation.

\section{Histone Genes and Epigenetics Evolution}

Gene structure of the two histone types is very different. Large amounts of the canonical histones need to be produced within a short period during early development in Drosophila. This can be accomplished by multiple gene copies, tandem gene clusters, and no splicing. On the other hand, large amounts of the replacement histones are not required; however, they should be expressed at the proper time. Therefore, for the replacement histones, a single or a few gene copies should be sufficient or better than multiple gene copies.

Exon-intron structure is also remarkably different between the genes of the two histone types; no intron has been found for the canonical type, but 1-4 introns have been found for the replacement type. Therefore, control of histone expression by splicing is only 
possible for the replacement type. Although the detailed mechanisms regarding the control of histone expression by splicing remains unknown, several conserved sequences at splicing sites have been found for the replacement type [87-89].

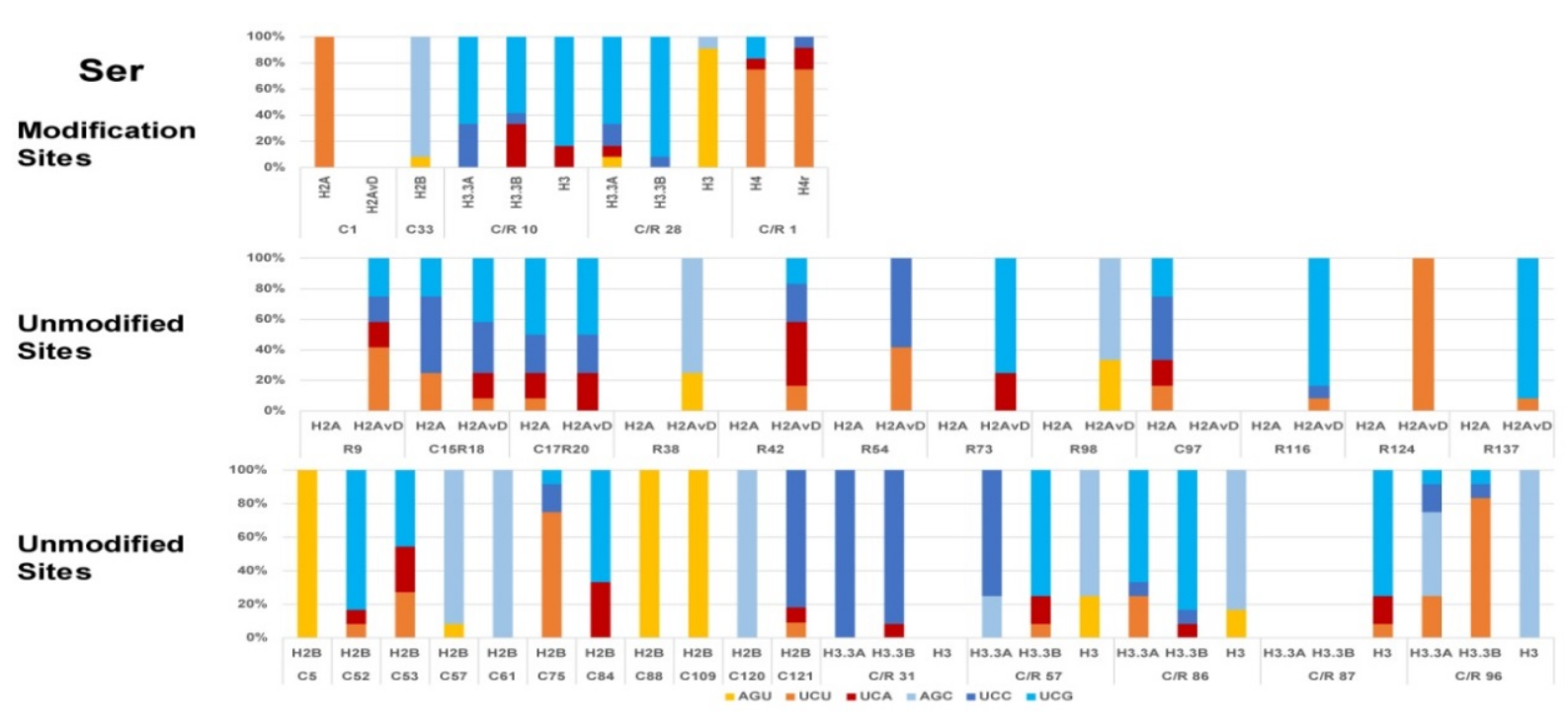

Figure 6: Codon usage for the modified or unmodified serine sites in histones summed over 12 Drosophila species. The position numbers for serines in the canonical (C) or replacement (R) histone types, and the codon usage for these serines are indicated. The codon usages (\%) are labeled with the same colours as in Figure 4.

Transcriptional control plays an important role in controlling the expression of the canonical type [19,69]. However, a transcriptional control region was not found in the upstream region of the genes for the replacement type histones $[87,88]$ except for the H2AvD gene [89]. Thus, for the replacement type histones, transcriptional control is only possible for the $\mathrm{H} 2 \mathrm{AvD}$ gene since this is the only replacement type histone gene to have a conserved transcriptional control sequence upstream of the H2AvD gene [89].

Another difference between canonical and replacement type histones is their codon usage. The replacement type used $\mathrm{G}$ or $\mathrm{C}$ at the 3rd codon position more often than the canonical type. Codon use may affect the translation efficiency in conjunction with the composition of tRNA pools in the cell. Furthermore, the extraordinary biased codon usage at the sites of histone modification suggested a functional difference in codon usage.

\section{Acknowledgements}

I would like to express my thanks to the researchers who carried out the studies of histone genes in Drosophila for their cooperation, especially to Yoshinori Yamamoto, Toru Watanabe, Yuki Saito, Mayu Nakamura, and Norikazu Kakubayashi.

\section{References}

1. Schümperli D (1986) Cell-cycle regulation of histone gene expression Cell 45: 471-472.

2. Black BE, Foliz DR, Chakravarthy S, Luger K, Woods VL, et al. (2004) Structural determinants for generating centromeric chromatin. Nature 430: $578-582$.

3. Blower MD, Karpen GH (2001) The role of Drosophila CID in kinetochore formation, cell-cycle progression and heterochromatin interactions. Nat Cell Biol 3: 730-739.
4. Heun P, Erhardt S, Blower MD, Weiss S, Skora AD, et al. (2006) Mislocalization of the Drosophila centromere-specific histone CID promotes formation of functional ectopic kinetochores. Dev Cell 10: 303-315.

5. Malik HS, Henikoff S (2001) Adaptive evolution of Cid, a centromerespecific histone in Drosophila. Genetics 157: 1293-1298.

6. Mizuguchi G, Xiao H, Wisniewski J, Smith MM, Wu C (2007) Nonhistone $\mathrm{Scm} 3$ and Histones CenH3-H4 Assemble the Core of CentromereSpecific Nucleosomes. Cell 129: 1153-1164.

7. Moreno-Moreno O, Medina-Giró S, Torras-Llort M, Azorín F (2011) The F box protein partner of paired regulates stability of Drosophila centromeric histone H3, CenH3 CID. Curr Biol 21: 1488-1493.

8. Palmer D, Snyder LA, Blumenfeld M (1980) Drosophila nucleosomes contain an unusual histone-like protein. Proc Natl Acad Sci USA 77: 2671-2675.

9. Galewsky S, Xie X, Schulz RA (1990) The Drosophila melanogaster z600 gene encodes a chromatin-associated protein synthesized in the syncytial blastoderm. Gene 96: 227-232.

10. Dalal Y, Furuyama T, Vermaak D, Henikoff S (2007) Structure, dynamics, and evolution of centromeric nucleosomes. Proc Natl Acad Sci USA 104: 15974-15981.

11. Pérez-Montero S, Carbonell A, Morán T, Vaquero A, Azorín F (2013) The embryonic linker histone H1 variant of Drosophila, dBigH1, regulates zygotic genome activation. Dev Cell 26: 578-590.

12. Weber CM, Henikoff S (2014) Histone variants: dynamic punctuation in transcription. Genes Dev 28: 672-682.

13. Cooper JL, Henikoff S (2004) Adaptive evolution of the histone fold domain in centromeric histones. Mol Biol Evol 21: 1712-1718.

14. Dunleavy EM, Roche D, Tagami H, Lacoste N, Ray-Gallet D, et al. (2009) HJURP is a cell-cycle-dependent maintenance and deposition factor of CENP-A at centromeres. Cell 137: 485-497.

15. Karpen GH, Allshire RC (1997) The case for epigenetic effects on centromere identity and function. Trends Genet 13: 489-496.

16. Tachiwana H, Miya Y, Shono N, Ohzeki J-I, Osakabe A, et al. (2013) Nap1 regulates proper CENP-B binding to nucleosomes. Nucleic Acids Res 41: 2869-2880. 
17. Fujita R, Otake K, Arimura Y, Horikoshi N, Miya Y, et al. (2015) Stable complex formation of CENP-B with the CENP-A nucleosome. Nucleic Acids Res 43: 4909-49022.

18. Akhmanova A, Hennig W (1998) Drosophila melanogaster histone H2B retropseudogene is inserted into a region rich in transposable elements. Genome 41: 396-401.

19. Matsuo Y (2006) Genomic structure and evolution of the histone gene family in Drosophila. Curr Top Genet 2: 1-14.

20. Feng S, Jacobsen SE, Reik W (2010) Epigenetic Reprogramming in Plant and Animal Development. Science 330: 622-627.

21. Rothbart SB, Strahl BD (2014) Interpreting the language of histone and DNA modifications. Biochim Biophys Acta 1839: 627-643.

22. Chen ZJ (2013) Genomic and epigenetic insights into the molecular bases of heterosis. Nat Rev Genet 14: 471-482.

23. Smith ZD, Meissner A (2013) DNA methylation: Roles in mammalian development. Nat Rev Genet 14: 204-220.

24. Cantone I, Fisher AG (2013) Epigenetic programming and reprogramming during development. Nat Struct Mol Biol 20: 282-289.

25. Portela A, Esteller M (2010) Epigenetic modifications and human disease. Nat Biotechnol 28: 1057-1068.

26. Lawrence M, Daujat S, Schneider R (2016) Lateral Thinking: How Histone Modifications Regulate Gene Expression. Trends Genet 32: 42-56.

27. Domier LL, Rivard JJ, Sabatini LM, Blumenfeld M (1986) Drosophila virilis histone gene clusters lacking H1 coding segments. J Mol Evol 23: 149-58.

28. Soboleva TA, Nekrasov M, Ryan DP, Tremethick DJ (2014) Histone variants at the transcription start-site. Trends Genet 30: 199-209.

29. Jenuwein T, Allis CD (2001) Translating the Histone Code. Science 293: 1074-1080.

30. Musselman CA, Lalonde ME, Côté J, Kutateladze TG (2012) Perceiving the epigenetic landscape through histone readers. Nat Struct Mol Biol 19: 1218-1227.

31. Tanabe M, Kouzmenko AP, Ito S, Sawatsubashi S, Suzuki E, Fujiyama S, et al. (2008) Activation of facultatively silenced Drosophila loci associates with increased acetylation of histone H2AvD. Genes to Cells 13: 1279-1288.

32. Benson LJ, Gu Y, Yakovleva T, Tong K, Barrows C, Strack CL, et al. (2006) Modifications of $\mathrm{H} 3$ and $\mathrm{H} 4$ during chromatin replication, nucleosome assembly, and histone exchange. J Biol Chem 281: 9287- 9296.

33. Santoro SW, Dulac C (2015) Histone variants and cellular plasticity. Trends Genet 31: 516-527.

34. Biterge B, Schneider R (2014) Histone variants: Key players of chromatin. Cell Tissue Res 356: 457-466.

35. Maze I, Noh KM, Soshnev AA, Allis CD (2014) Every amino acid matters: Essential contributions of histone variants to mammalian development and disease. Nat Rev Genet 15: 259-271.

36. Henikoff S (2008) Nucleosome destabilization in the epigenetic regulation of gene expression. Nat Rev Genet 9: 15-26.

37. Kotova E, Lodhi N, Jarnik M, Pinnola AD, Ji Y, Tulin AV (2011) Drosophila histone $\mathrm{H} 2 \mathrm{~A}$ variant (H2Av) controls poly(ADP-ribose) polymerase 1 (PARP1) activation. Proc Natl Acad Sci U S A 108: 6205-6210.

38. Talbert PB, Henikoff S (2014) Environmental responses mediated by histone variants. Trends Cell Biol 24: 642-650.

39. Prado JRM, Srinivasan S, Fuller MT (2013) The Histone Variant His2Av is Required for Adult Stem Cell Maintenance in the Drosophila Testis. PLoS Genet 9: 1-13.

40. Isenberg I (1979) Histones. Ann Rev Biochem 48: 159-191

41. Kornberg RD (1977) Structure of Chromatin. Annu Rev Biochem 46: 931-954.

42. Li B, Pattenden SG, Lee D, Gutiérrez J, Chen J, Seidel C, et al. (2005) Preferential occupancy of histone variant $\mathrm{H} 2 \mathrm{AZ}$ at inactive promoters influences local histone modifications and chromatin remodeling. Proc Natl Acad Sci U S A 102: 18385-18390.

43. Hennig W, Weyrich A (2013) Histone modifications in the male germ line of Drosophila. BMC Dev Biol 13: 1-14.

44. Loyola A, Almouzni G (2007) Marking histone H3 variants: How, when and why? Trends Biochem Sci 32: 425-433.

45. Zentner GE, Henikoff S (2013) Regulation of nucleosome dynamics by histone modifications. Nat Struct Mol Biol 20: 259-266.

46. Cedar H, Bergman Y (2009) Linking DNA methylation and histone modification: Patterns and paradigms. Nat Rev Genet 10: 295-304

47. Becker PB, Workman JL (2013) Nucleosome remodeling and epigenetics. Cold Spring Harb Perspect Biol 5: 1-19.

48. Venkatesh S, Workman JL (2015) Histone exchange, chromatin structure and the regulation of transcription. Nat Rev Mol Cell Biol 16: 178-189.

49. Gaume X, Torres-Padilla ME (2016) Regulation of reprogramming and cellular plasticity through histone exchange and histone variant incorporation. Cold Spring Harbor Symposia on Quantitative Biology 80: 165-175.

50. Henikoff S (2009) Epigenetic profiling of histone variants. Epigenomics pp 101-118.

51. Grunstein M (1997) Histone acetylation in chromatin structure and transcription. Nature 389: 349-352.

52. Kouzarides $\mathrm{T}$ (2007) Review Chromatin Modifications and Their Function. Cell 128: 693-705

53. Riddle NC, Minoda A, Kharchenko PV, Alekseyenko AA, Schwartz YB, et al. (2011) Plasticity in patterns of histone modifications and chromosomal proteins in Drosophila heterochromatin. Genome Res 21: 147-163.

54. Zhang C, Gao S, Molascon AJ, Liu Y, Andrews PC (2014) Quantitative proteomics reveals histone modifications in crosstalk with h3 lysine 27 methylation. Mol Cell Proteomics 13: 749-759.

55. Mito Y, Henikoff JG, Henikoff S (2005) Genome-scale profiling of histone H3.3 replacement patterns. Nat Genet 37: 1090-1097.

56. Henikoff S, Furuyama T, Ahmad K (2004) Histone variants, nucleosome assembly and epigenetic inheritance. Trends Genet 20: 320-326.

57. Hennig W (2003) Chromosomal proteins in the spermatogenesis of Drosophila. Chromosoma 8: 489-494.

58. Santenard A, Torres-Padilla ME (2009) Epigenetic reprogramming in mammalian reproduction: Contribution from histone variants. Epigenetics 4: 80-84.

59. Kurumizawa H, Horikoshi N, Tachiwana H, Kagawa W (2013) Current progress on structural studies of nucleosomes containing histone $\mathrm{H} 3$ variants. Curr Opin Struct Biol 23: 109-115.

60. Baldi S, Becker PB (2013) The variant histone H2A.V of DrosophilaThree roles, two guises. Chromosoma 122: 245-258.

61. Yuan G, Zhu B (2012) Histone variants and epigenetic inheritance. Biochim Biophys Acta-Gene Regul Mech 1819: 222-229.

62. Filipescu D, Szenker E, Almouzni G (2013) Developmental roles of histone $\mathrm{H} 3$ variants and their chaperones. Trends Genet 29: 630-640.

63. Henikoff S, Smith MM (2015) Histone variants and epigenetics. Cold Spring Harb Perspect Biol 7: 1-26.

64. Cheema MS, Ausió J (2015) The structural determinants behind the epigenetic role of histone variants. Genes (Basel) 6: 685-713.

65. Akhmanova A, Miedema K, Hennig W (1996) Identification and characterization of the replacement gene Drosophila histone H4. 388: 219-222.

66. van Daal A, White EM, Gorovsky MA, Elgin CR (1988) Drosophila has a single copy of the gene encoding a highly conserved histone $\mathrm{H} 2 \mathrm{~A}$ variant of the H2A. F/Z type. Nucleic Acids Res 16: 7487- 7497.

67. Fretzin S, Allan BD, van Daal A, Elgin SCR (1991) A Drosophila melanogaster $\mathrm{H} 3.3 \mathrm{cDNA}$ encodes a histone variant identical with the vertebrate H3.3. Gene 107: 341-342. 
68. Akhmanova AS, Bindels PCT, Xu J, Miedema K, Kremer H, Hennig W, et al. (1995) Structure and expression of histone H3.3 genes in Drosophila melanogaster and Drosophila hydei. Genome 38: 586-600.

69. Matsuo Y, Yamazaki T (1989) tRNA derived insertion element in histone gene repeating unit of Drosophila melanogaster. Nucleic Acids Res 17: 225-38.

70. Matsuo Y, Yamazaki T (1989) Nucleotide variation and divergence in the histone multigene family in Drosophila melanogaster. Genetics 122: 87-97.

71. Kremer H, Hennig W (1990) Isolation and characterization of a Drosophila hydei histone DNA repeat unit. Nucleic Acids Res 18: 1573-1586.

72. Fitch DH, Strausbaugh LD (1993) Low codon bias and high rates of synonymous substitution in Drosophila hydei and D. melanogaster histone genes. Mol Biol Evol 10: 397-413.

73. Tsunemoto K, Matsuo Y (2001) Molecular evolutionary analysis of a histone gene repeating unit from Drosophila simulans. Genes Genet Syst 76: 355-61.

74. Kakita M, Shimizu T, Emoto M, Nagai M, Takeguchi M, Hosono Y, et al (2003) Divergence and heterogeneity of the histone gene repeating units in the Drosophila melanogaster species subgroup. Genes Genet Syst 78: 383-389.

75. Nagoda N, Fukuda A, Nakashima Y, Matsuo Y (2005) Molecular characterization and evolution of the repeating units of histone genes in Drosophila americana: coexistence of quartet and quintet units in a genome. Insect Mol Biol 14: 713-7.

76. Nakashima Y, Higashiyama A, Ushimaru A, Nagoda N, Matsuo Y (2016) Evolution of GC content in the histone gene repeating units from Drosophila lutescens, D. takahashii and D. pseudoobscura. Genes Genet Syst 91: 27-36

77. Kakubayashi, N, Fujita, E, Morikawa, M, Ohashi, S and Matsuo Y (2017) Concerted Evolution of the Replication-Dependent Histone Gene Family in Drosophila immigrans. J Data Mining Genomics Proteomics OMICS International 8: 1-7.

78. Matsuo Y (2000) Molecular Evolution of the Histone 3 Multigene Family in the Drosophila melanogaster Species Subgroup. Mol Phylogenet Evol 16: 339-343.

79. Pardue ML, Kedes LH, Weinberg ES, Birnstiel ML (1977) Localization of sequences coding for histone messenger RNA in the chromosomes of Drosophila melanogaster. Chromosoma Springer-Verlag; 63: 135-151.

80. Lifton RP, Goldberg ML, Karp RW, Hogness DS (1978) The Organization of the Histone Genes in Drosophila melanogaster. Functional and Evolutionary Implications. Cold Spring Harb Symp Quant Biol 42: 1047-1051.
81. Schienman JE, Lozovskaya ER, Strausbaugh LD (1998) Drosophila virilis has atypical kinds and arrangements of histone repeats. Chromosoma 107: 529-39.

82. Nagel S, Grossbach U (2000) Histone H1 genes and histone gene clusters in the genus Drosophila. J Mol Evol 51: 286-298.

83. Albig W, Warthorst U, Drabent B, Prats E, Cornudella L, Doenecke D (2003) Mytilus edulis core histone genes are organized in two clusters devoid of linker histone genes. J Mol Evol 56: 597- 606.

84. Sabath I, Skrajna A, Yang X, Dadlez M, Marzluff WF, Dominski Z (2013) 3 '-End processing of histone pre-mRNAs in Drosophila: U7 snRNP is associated with FLASH and polyadenylation factors :1726-1744.

85. Marzluff WF, Wagner EJ, Duronio RJ (2008) Metabolism and regulation of canonical histone mRNAs: life without a poly(A) tail. Nat Rev Genet 9: 843-854.

86. Akhmanova A, Miedema K, Kremer H, Hennig W (1997) Two types of polyadenated mRNAs are synthesized from Drosophila replicationdependent histone genes. Eur J Biochem 244: 294-300.

87. Yamamoto Y, Watanabe T, Nakamura M, Kakubayashi N, Saito Y, Matsuo Y (2016) Epigenetics Evolution and Replacement Histones: Evolutionary Changes at Drosophila H4r. J Phylogenetics Evol Biol OMICS International 4: 1-9.

88. Matsuo Y, Kakubayashi N (2016) Epigenetics Evolution and Replacement Histones: Evolutionary Changes at Drosophila H3.3A and H3.3B. J Phylogenet Evol Biol OMICS International 4: 1-8.

89. Matsuo Y and Kakubayashi N (2017) Epigenetics Evolution and Replacement Histones: Evolutionary Changes at Drosophila H2AvD. J Data Mining Genomics Proteomics OMICS International 8: 1-10.

90. Matsuo Y (2000) Evolutionary change of codon usage for the histone gene family in Drosophila melanogaster and Drosophila hydei. Mol Phylogenet Evol 15: 283-91.

91. Matsuo Y (2003) Evolution of the GC content of the histone 3 gene in seven Drosophila species. Genes Genet Syst 78: 309-318.

92. Singh ND, Arndt PF, Petrov DA (2006) Minor shift in background substitutional patterns in the Drosophila saltans and willistoni lineages is insufficient to explain GC content of coding sequences. BMC Biol 4: 1-14.

93. Vicario S, Moriyama EN, Powell JR (2007) Codon usage in twelve species of Drosophila. BMC Evol Biol 17: 1-17.

94. Li KK, Luo C, Wang D, Jiang H, Zheng YG (2012) Chemical and biochemical approaches in the study of histone methylation and demethylation. Med Res Rev 32: 815-867.

95. Rivera C, Saavedra F, Alvarez F, Díaz-Celis C, Ugalde V, Li J, et al. (2015) Methylation of histone H3 lysine 9 occurs during translation. Nucleic Acids Res 43: 9097-9106.
This article was originally published in a special issue, entitled: "Trends of Evolutionary biology \& Molecular Phylogenetics", Edited by Luciano Brocchieri 